\title{
Satisfaction and stress levels of dentistry students relating to distance education
}

\author{
Ayşe Tuğba Ertürk Avunduk ${ }^{1, A-F}$, Ebru Delikan ${ }^{2, A-F}$ \\ ${ }^{1}$ Department of Restorative Dentistry, Faculty of Dentistry, Mersin University, Turkey \\ ${ }^{2}$ Department of Pediatric Dentistry, Faculty of Dentistry, Nuh Naci Yazgan University, Kayseri, Turkey \\ A - research concept and design; $\mathrm{B}$ - collection and/or assembly of data; $\mathrm{C}$ - data analysis and interpretation; \\ $D$ - writing the article; $E$ - critical revision of the article; $F$ - final approval of the article
}

Address for correspondence

Ayşe Tuğba Ertürk Avunduk

E-mail: aysetugba11@gmail.com

Funding sources

None declared

Conflict of interest

None declared

Acknowledgements

The authors thank all young dentist colleagues who contributed to the work, and also biostatistics specialist Çağla Sarıtürk for her kind support during the statistical analysis.

Received on February 24, 2021

Reviewed on March 26, 2021

Accepted on March 31, 2021

Published online on June 15, 2021

Cite as

Ertürk Avunduk AT, Delikan E. Satisfaction and stress levels of dentistry students relating to distance education. Dent Med Probl. 2021;58(3):291-298. doi:10.17219/dmp/135318

DOI

$10.17219 / \mathrm{dmp} / 135318$

Copyright

๑ 2021 by Wroclaw Medical University

This is an article distributed under the terms of the

Creative Commons Attribution 3.0 Unported License (CC BY 3.0)

(https://creativecommons.org/licenses/by/3.0/)

\begin{abstract}
Background. It is not known whether the coronavirus disease 2019 (COVID-19) pandemic has affected dentistry education.

Objectives. This study aimed to determine the satisfaction and stress levels of dentistry students in Turkey regarding distance education during the COVID-19 pandemic, and to evaluate their opinions on this matter.

Material and methods. This cross-sectional research study was conducted from October to November 2020 with the use of a web-based questionnaire consisting of 3 sections. The $11^{\text {st }}$ section focused on demographic data. The $2^{\text {nd }}$ section evaluated dentistry students' opinions regarding distance education during the pandemic; it comprised 8 multiple-choice questions and 1 open-ended question. The $3^{\text {rd }}$ section referred to the 10-item Perceived Stress Scale (PSS-10), which is intended to assess the stress levels. The data was subjected to the descriptive statistical analysis, the $x^{2}$ tests and the logistic regression analysis.

Results. The sample consisted of 919 dentistry students, reflecting a response rate of $84 \%$. Of the total sample, $81.6 \%$ of the participants were studying at state universities and more than half were female. These students' perceived stress levels were significantly increased due to the following factors: education at a state school; insufficient technical opportunities at home/dormitory facilities; decreased support from the academic staff of the universities during distance education; and a low level of knowledge of online document usage $(p<0.05)$. The evaluation of the responses to the open-ended question indicated that the difficulties encountered by highly stressed students during distance education were mostly adaptationrelated $(p=0.011$ ). The logistic regression analysis showed that gender was significantly associated with high stress levels $(p<0.05)$.
\end{abstract}

Conclusions. The data showed that dentistry students preferred hybrid education and were unsatisfied with their experience with distance education.

Keywords: dental students, distance education, COVID-19, Perceived Stress Scale 


\section{Introduction}

Coronavirus disease 2019 (COVID-19) is a new illness caused by severe acute respiratory syndrome coronavirus 2 (SARS CoV-2), ${ }^{1}$ a member of the Coronaviridae family, that emerged in Wuhan, Hubei Province in China in December 2019. ${ }^{2}$ COVID-19 has created a public health problem, affecting not only China, but the whole world. It spread widely to different countries, prompting the World Health Organization (WHO) to declare its occurrence a pandemic on March 11, 2020. ${ }^{3}$ The rapid spread of the virus, the ensuing threat to the entire world and its effects on the global economy have led to the implementation of different measures and practices, such as strict protective management and regulation through social distancing, flight bans and quarantine.

In dentistry, most treatment procedures involve the production of droplets and/or aerosols, which can cause infection; thus, the pandemic has also affected dentistry education. Governments and institutions have had to take swift and draconian measures for continuing education, and transition from face-to-face learning to distance learning. ${ }^{4}$ In distance education, students can benefit from remotely available educational opportunities, but there is a lack of face-to-face interactions, group work, classroom activities, responsibilities, and social development. In this type of educational delivery, students may encounter problems, such as the absence of timely and continuous support services, a lack of extracurricular social activities, insufficient communication infrastructure, and the inability to manage time effectively because of lecture intensity. Lecturer-induced problems can also arise, including the lecturer's inability to adapt to technology, a lack of preparation for studentcentered content and the ineffective use of communication tools. ${ }^{5}$ Dentistry education involves pre-clinical and clinical practice as well as theoretical lectures. It is a hands-on type of learning involving teaching clinics, which requires a very high teacher-to-student ratio. ${ }^{6}$ Accordingly, the health and safety of patients, students and staff are very important. The COVID-19 pandemic has led to the reconsideration of many aspects of clinical training, including the organization of dental clinics, the control of aerosol release and airflow, the extension of clinical decontamination time, and the review of appropriate personal protective equipment (PPE). ${ }^{7}$ Shortcomings in these respects mean that some faculties are unable to provide sufficient amount of knowledge and skills to dentistry students within distance education.

In different countries, various studies have been conducted on the perceptions of university students, their experiences of significant changes in the educational system and the distance education process, and their satisfaction with this educational delivery method. ${ }^{5,8,9}$ These unexpected changes have evoked stress among students. Considering the effects of stress on human health, a necessary task is to measure and quantify this condition. One of the most frequently used measurement instruments for this purpose is the Perceived Stress Scale (PSS) ${ }^{10}$ developed by Cohen et al. ${ }^{11}$

Although studies on the stress levels and perceptions of dentistry students during the COVID-19 pandemic have been conducted, no such research has been carried out in Turkey. The present work was therefore initiated to determine the stress levels in dentistry students, and their satisfaction with theoretical and practical classes under distance education conditions during the pandemic.

\section{Material and methods}

This cross-sectional study was conducted from October to November 2020 with the use of a web-based survey. The research protocol was approved by the Ethics Committee of Mersin University, Turkey, and was executed in accordance with the most recent guidelines of the Declaration of Helsinki. The study was also performed following the STROBE (Strengthening the Reporting of Observational Studies in Epidemiology) guidelines. ${ }^{12}$ The sample size was calculated on the basis of the total number of dentistry students $(21,305)$ enrolled at the dentistry faculties from 2016 to 2020 who were included in the distance education process as part of their institutions' response to the pandemic (www.openepi.com/SampleSize). The assumption of a 50\% response rate and $95 \%$ confidence intervals $(C I)$ yielded a minimum sample of 378 randomly selected individuals as a requirement.

An electronic questionnaire (Google Forms) was prepared by modifying the questionnaires previously validated by Rahali et al., ${ }^{13}$ Asiry, ${ }^{9}$ and Halim and Sulaiman. ${ }^{14}$ A pilot test involving 30 students indicated no need for any adjustments to the questionnaire. Respondents for the web-based questionnaire were selected via probability sampling from a closed population list. ${ }^{15}$ The eligibility criteria were as follows: currently a dentistry student; over the age of 18; consented to participate in the study; and the completion of the questionnaire. Students under the age of 18 were excluded from this study (Fig. 1). A link to the questionnaire was sent to dentistry students at state

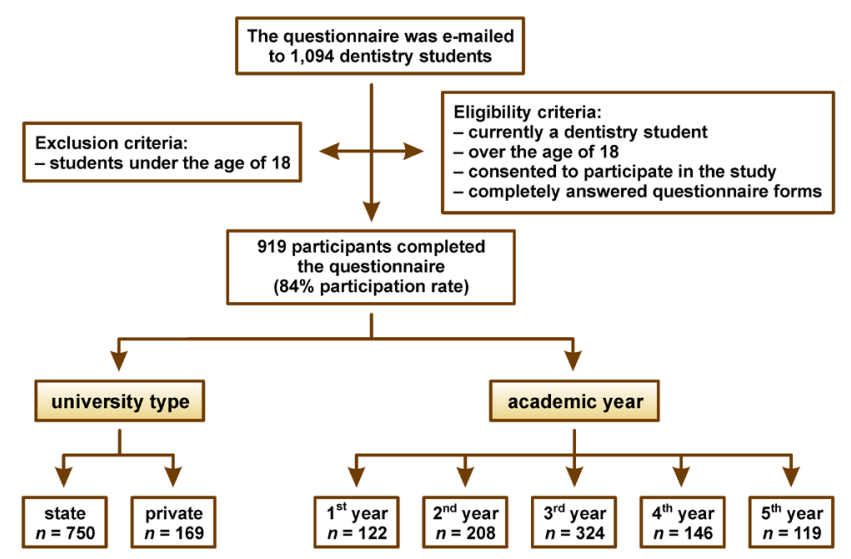

Fig. 1. Flowchart of the sample selection process 
and private universities in Turkey via e-mail, an Internet communicator (WhatsApp) and social media. A reminder message was sent a week later to increase the participation rate and minimize the risk of bias.

The developed questionnaire consisted of 3 sections. Following the explanation of the purpose of the survey, the $1^{\text {st }}$ section focused on the demographic data (gender, university type and academic year) of the participants (Table 1). The $2^{\text {nd }}$ section was devoted to the students' opinions on distance education during the COVID-19 pandemic. It comprised 8 multiple-choice questions and 1 open-ended question. A Likert scale ranging from 1 to 5 was used as the response method for opinion-related questions (i.e., 1 - strongly disagree; 2 - disagree; 3 - uncertain; 4 - agree; and 5 - strongly agree). The major problem faced by the students during the distance education process was extracted through the open-ended question. The answers were categorized in terms of obstacles as follows: technical; financial; adaptation; practical training; pedagogical; and other (Table 1 ). The $3^{\text {rd }}$ section of the questionnaire consisted of the 10-item PSS (PSS-10), which was designed to evaluate the stress levels of students as they deal with distance education. The PSS-10 referred to the students' thoughts and feelings over the previous month, using a 0-4 response scale. ${ }^{16}$ The PSS-10 covers 2 factors - the first one comprises 6 negative items measuring an individual's stress perception, whereas the other one comprises 4 positive items measuring coping or adaptation to stress. ${ }^{17}$ The scores assigned to questions $1,2,3,6,9$, and 10 reflect a response scale of $0-4$ ( 0 - never; 1 - hardly ever; 2 -sometimes; 3 - often; and 4 - very often) and are as follows: 0 - 0; 1 - 1; $2-2 ; 3-3$; and $4-4$. Answers to the remaining questions are reverse-scored. Individual scores on the PSS-10 can thus range from 0 to 40, with higher scores indicating greater perceived stress. Scores in the ranges of 0-13, 14-26 and 27-40 are considered indicative of low, moderate and high perceptions of stress, respectively (Table 1).

Table 1. Demographic data of the participants and questionnaire items related to distance education

\begin{tabular}{|lc}
\multicolumn{1}{l}{ Questionnaire items } & $n(\%)$ \\
\hline Gender & \\
- female & $542(59.0)$ \\
- male & $377(41.0)$ \\
University type & \\
- state & $750(81.6)$ \\
- private & $169(18.4)$ \\
Academic year & \\
- $1^{\text {st }}$ & $122(13.3)$ \\
- 2 & $208(22.6)$ \\
- 3rd & $324(35.3)$ \\
- $4^{\text {th }}$ & $146(15.9)$ \\
- $5^{\text {th }}$ & $119(12.9)$ \\
Preferred device for participating in distance education & \\
- cellphone & $272(29.6)$ \\
- computer & $183(19.9)$ \\
- laptop & $447(48.6)$ \\
- tablet & $17(1.8)$ \\
\hline
\end{tabular}

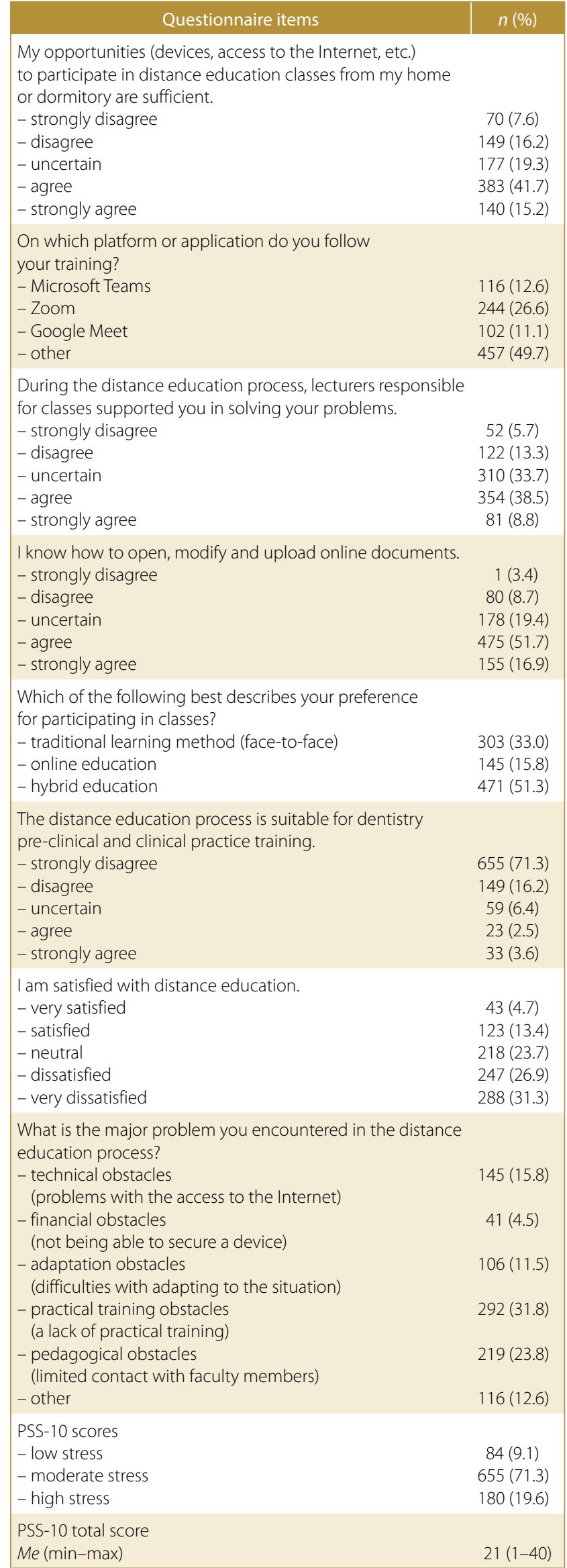

PSS-10 - 10-item Perceived Stress Scale; Me - median; min - minimum; max-maximum 


\section{Statistical analyses}

Statistical analyses were performed using the IBM SPSS Statistics for Windows software, v. 25.0 (IBM Corp., Armonk, USA). Categorical measurements were summarized as numbers and percentages, whereas continuous measurements were expressed as median and minimummaximum. The $X^{2}$ tests were conducted to compare categorical variables. The logistic regression analysis was performed to determine independent risk factors that affect stress perceptions. The level of statistical significance was set at $p=0.05$.

\section{Results}

The questionnaire was e-mailed to 1,094 dentistry students. Completed forms were received from 919 students, resulting in a response rate of $84 \%$. Of the total sample, $81.6 \%$ of the participants were studying at state universities and more than half were female. A total of $35.3 \%$ of the participants were in their $3^{\text {rd }}$ year of studies, whereas the rest were in their $2^{\text {nd }}(22.6 \%), 4^{\text {th }}(15.9 \%), 1^{\text {st }}(13.3 \%)$, or $5^{\text {th }}(12.9 \%)$ academic year (Table 1$)$.

Table 2 presents the PSS-10 scores of the participants. The stress levels of female students were significantly higher than those of male students $(p=0.0001)$. The stress levels of students at state universities were significantly higher than those of students enrolled at private universities $(p=0.034)$. As opportunities to attend remote classes from home or dormitories decreased, the stress levels of the students significantly increased $(p=0.0001)$. In addition, as the level of support provided by lecturers to the students decreased, the students' stress levels increased significantly $(p=0.0001)$. The comparison of knowledge regarding how to open, modify and upload online documents between the stress groups indicated that the stress levels of students with a low level of technological knowledge were significantly higher than those of other students $(p=0.0001)$. As the stress levels increased, student preference for traditional education also significantly increased $(p=0.042)$. The stress arising from concerns that distance education is unsuitable for pre-clinical and clinical training was significantly high $(p=0.0001)$. The evaluation of the responses to the open-ended question reflected that the problems encountered by highly stressed students were mostly adaptation-related $(p=0.011)$.

The results of the logistic regression analysis are shown in Table 3. For the analysis, all the parameters identified as statistically significant in Table 2 were added to the model. The results confirmed that gender, type of university, support from lecturers, satisfaction with distance education, and adaptation-related obstacles were significant factors related to students' opinions regarding distance learning. Among all the predictor variables, gender was most significantly associated with high stress levels, with female students experiencing high stress 2.6 times (95\% CI: 1.8-3.9) more frequently than male students.

\section{Discussion}

The COVID-19 pandemic has affected the education of more than 770 million students around the world due to the almost complete closure of schools, universities and colleges. ${ }^{4}$ The most frequently encountered obstacles in the distance education models implemented during this period are technical, financial, adaptation-related, or pedagogical in nature. ${ }^{13}$ Additionally, the difficulties associated with practical classes have increased exponentially, as is the case for dentistry faculties, where pre-clinical and clinical training are crucial. Pre-clinical training has been provided to some extent, but clinical training has been suspended by most faculties. ${ }^{18}$ Deficiencies in theoretical, pre-clinical and clinical training, together with the fear of professional inadequacy, can evoke stress among dentistry students. The main purpose of our research was to evaluate the satisfaction and stress levels of dentistry students in Turkey regarding the distance education process compelled by the restrictions imposed by the COVID-19 crisis.

The use of questionnaires to evaluate the satisfaction and stress levels of dentistry students is a valid research method. 9,13,19,20 Web-based questionnaires are reported to have lower response rates than paper-based questionnaires. ${ }^{21}$ To minimize the risk of bias in survey studies, researchers should achieve an optimum response rate of $70-80 \%{ }^{22}$ - a level that was exceeded in the current study (84\%). Another important requirement is an adequate sample size. In previous studies conducted in different countries, the sample sizes were as follows: $832^{20} ; 70^{9}$; $200^{19} ; 123^{13} ; 450^{8} ; 230^{21} ; 310^{23}$; and $92 .^{24}$ The participation rate in the present research study was high and the sample size was 919.

There are 3 popular stress measurement tools: the Stress Appraisal Measure (SAM); the Impact of Event Scale (IES); and the PSS. The PSS is the most commonly used scale. ${ }^{10}$ It was initially developed as a 14-item scale that evaluated a participant's perceptions of the stressful events and situations which occurred in the previous month. The 4-item PSS (PSS-4) and the PSS-10 were later developed as shorter versions of the original scale. In our study, the PSS-10 was chosen due to concerns that participants would feel bored with an instrument containing too many questions and become distracted. On the other hand, we did not think the PSS-4 was sensitive enough to measure the stress levels.

The literature indicates differences in general stress levels between genders, with females showing higher stress levels than males. ${ }^{25}$ Varying experiences regarding the educational system during the pandemic induced different stress levels among female and male students in our study. 
Table 2. Comparison of the PSS-10 scores according to demographic variables and students' opinions on distance education

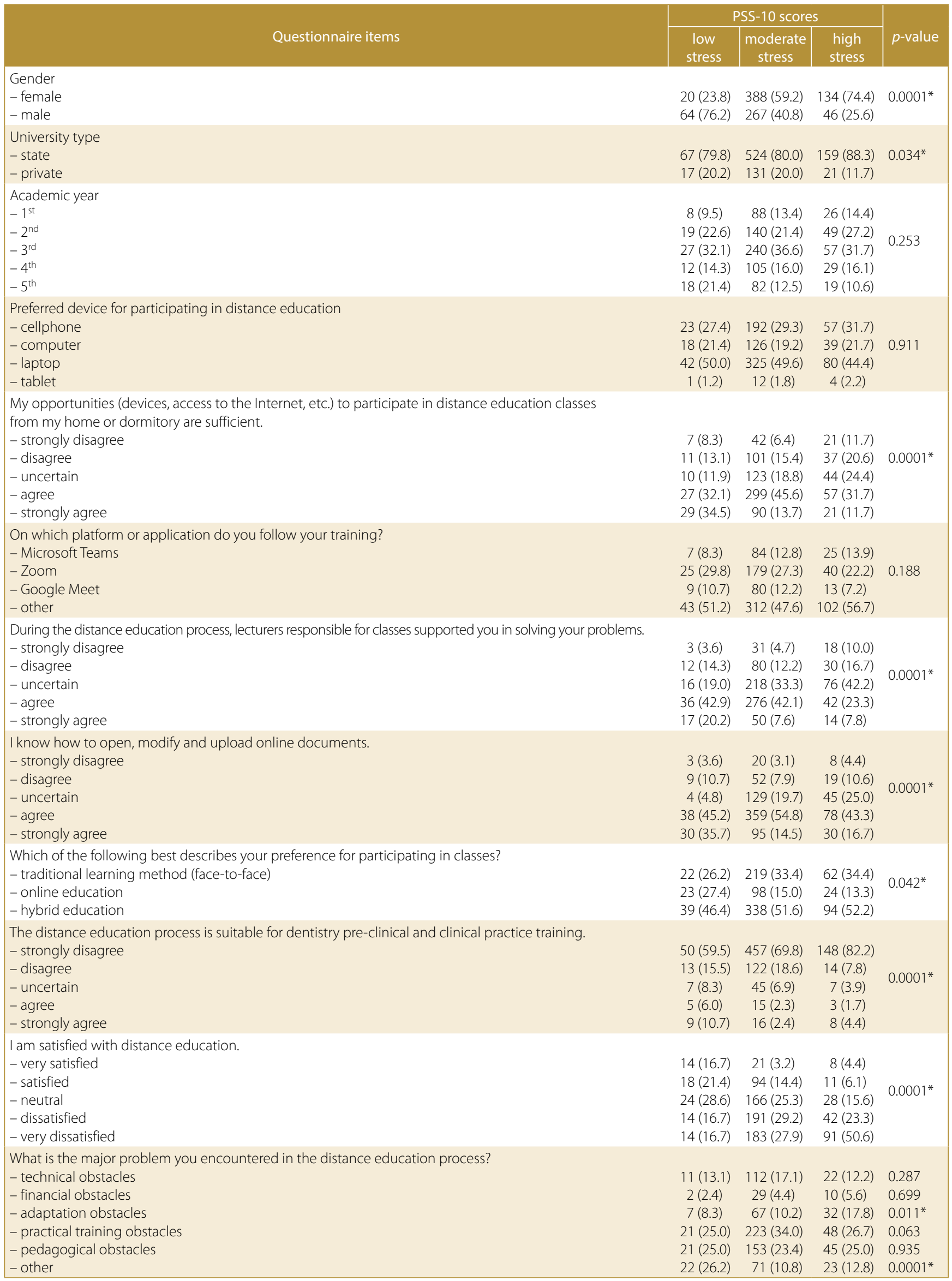

* statistically significant ( $x^{2}$ tests).

Data presented as number (percentage) ( $n(\%))$. 
Table 3. Factors associated with the students'stress levels according to the PSS-10 scores

\begin{tabular}{|c|c|c|c|c|}
\hline \multirow{2}{*}{ Factors associated with the students' stress levels } & \multirow{2}{*}{$p$-value } & \multirow{2}{*}{ OR } & \multicolumn{2}{|c|}{$95 \% \mathrm{Cl}$ for $O R$} \\
\hline & & & lower & upper \\
\hline Gender & $0.000^{*}$ & 2.633 & 1.795 & 3.864 \\
\hline University type & $0.046^{*}$ & 1.658 & 1.087 & 2.784 \\
\hline During the distance education process, lecturers responsible for classes supported you in solving your problems & $0.007^{*}$ & 1.297 & 1.074 & 1.567 \\
\hline I am satisfied with distance education & $0.000^{*}$ & 1.461 & 1.195 & 1.768 \\
\hline Adaptation obstacles & $0.000^{*}$ & 2.440 & 1.500 & 3.960 \\
\hline Constant & $0.000^{*}$ & 0.030 & - & - \\
\hline
\end{tabular}

$O R$ - odds ratio; $\mathrm{Cl}$ - confidence interval; * statistically significant (logistic regression analysis).

The fact that male students exhibited lower stress levels in comparison with female students is accordant with the literature. However, we can only make suppositions as to the reasons for the considerably higher stress levels of female students. We attribute this phenomenon to the fact that female students do not feel as comfortable with technology as male students do.

When we evaluated the effect of type of university on differences in the stress levels, we found that the high stress levels of dentistry students from state universities were related to the limitations of these institutions and/or students. Most state universities were unprepared for the distance education process; they did not have sufficient infrastructure, which prevented them from organizing theoretical courses online. Although several months had passed since the onset of the pandemic, limited facilities (e.g., unsuitable clinical settings) hindered the initiation of clinical training at most state universities in Turkey. The better financial standing of private universities enabled these institutions to rapidly arrange the infrastructure required for distance education. Additionally, students from private universities had better opportunities (better devices, access to the Internet, etc.) to participate in distance education classes. Thus, they experienced lower stress than students from state universities.

Our study was conducted among students from various state and private universities in Turkey, and no significant differences in the stress levels were found between students in different academic years. We expected stress to increase as students progressed to a higher academic year. However, since dentistry education involves preclinical and clinical training from the $1^{\text {st }}$ to the $5^{\text {th }}$ year, the stress levels were similar across all academic levels. Previous studies involving dentistry students were conducted within just 1 academic term.,24 In this respect, the current study was able to evaluate the issue more comprehensively, as it included dental students from all academic years.

Inquiring into the students' abilities to attend distance education classes from their homes or dormitories, we uncovered that those with insufficient opportunities suffered from significantly higher stress levels. The study also ascertained the factors causing stress among the students by probing the most serious problem encountered during distance education. In this context, the main problem was the unsuitability of distance education as an avenue for practical dentistry training (pre-clinical and clinical). The participants thought that no virtual session could replicate the real experience with patients (practical training obstacles), which is similar to the findings of Iyer et al. ${ }^{26}$ Other major obstacles faced by the participants were pedagogical, technical and adaptation-related challenges. Our results are also consistent with those of Rahali et al., who reported that the experience of distance education led to the emergence of many technical, psychological and/or pedagogical barriers. ${ }^{13}$

A recent work, likewise, investigated the advantages, limitations and suggestions associated with e-learning for both students and faculty members during the COVID-19 pandemic. ${ }^{27}$ The participants indicated the inability of faculty members to teach psychomotor skills, resource overabundance and the mismanagement of the educational process as limitations of online learning. Whereas faculty members complained about a lack of feedback regarding students' understanding of a topic, students reported that their attention span during online learning was shorter as compared to face-to-face sessions. ${ }^{27}$ A study by Bourzgui et al. also emphasized that most dentistry students had insufficient teacher-student interactions during online classes, ${ }^{28}$ which supports the results of the above study.

In our study, one of the issues the students complained about was the insufficient interest of lecturers in distance education, or a complete lack of it. A study on the perceptions of online education among dentistry students before the pandemic revealed that most students (61.2\%) were unsatisfied with the quality of the online lessons and procedural videos provided to them, highlighting the need for further improvements. ${ }^{9}$ High-quality online tutorials are an important success factor for establishing an effective online learning system. This condition can be addressed by providing training to lecturers on how to use online teaching/learning tools. Trainers should also adapt to rapidly developing technology. 
Studies have revealed significant gender differences in attitudes toward technology. In general, men express more interest in technological innovations and exhibit more knowledge in this respect, while women report experiencing more difficulties and reduced interest in using technology. ${ }^{29,30}$ According to the logistic regression analysis in the present work, female students experienced more considerable stress than male students. The higher overall satisfaction of male students with e-learning and their lower stress levels might be related to the higher technological self-efficacy of these students. This finding confirms previous reports regarding the effects of lower perceived computer self-efficacy and higher computer anxiety among female students on their perceived satisfaction with distance education. ${ }^{24}$

In other studies on distance education among dentistry students, students' perceptions of this educational delivery system were mostly negative. ${ }^{5,9,13}$ Similarly, the present research registered a very low percentage of dentistry students (18.1\%) declaring satisfaction with distance education. Practical classes are critical for gaining professional competence in dentistry education and the insufficient amount of practice plays a substantial role in reducing students' satisfaction with distance education. In our study, the students identified practical training obstacles as the major problem they faced in distance education - a result in line with the literature. To address these concerns, the innovative platforms used for theoretical lectures (Zoom, Google Meet, etc.) can be integrated into practical training. Another valuable strategy is to share the recorded videos of laboratory simulations or demonstrations with dentistry students. Note that an equally important approach is to consider feedback from students regarding their understanding of the subject matter. In a study where video conferencing tools were combined with the simulated equipment, the feedback received from students was positive. ${ }^{31}$

Most of the students in Abbasi et al's work stated that they preferred face-to-face education, ${ }^{5}$ whereas most of our participants expressed preference for hybrid education over traditional learning. This difference can be ascribed to variations in the online provision of the practical training curriculum. In addition, it could be related to students' perceptions of the severity of the COVID-19 pandemic. We agree that hybrid teaching is the most suitable educational model during the pandemic for Generation $\mathrm{Z}$ students, who can easily use digital technologies and applications, and exhibit openness to technology. Faculty members should be educated in this regard to guarantee the effectiveness of distance education; we believe that such training can be useful in the delivery of theoretical and practical classes.

Considering the unexpected changes stemming from the pandemic, the findings of our study show that an important task in dentistry education is to continue to teach quality and adequate theoretical content. More systematic teaching methods regarding clinical practice can be developed by making changes to the curricula, and more research should be conducted to illuminate how distance dentistry education can be enhanced. This work is limited in that it did not compare the effectiveness of distance learning and face-to-face education. Further studies should evaluate the 2 modes of educational delivery in this regard.

\section{Conclusions}

Our findings showed that the abrupt closure of universities due to the COVID-19 pandemic had prompted enormous transformations in the dentistry education system. Dentistry students were concerned that their pre-clinical and clinical training would be insufficient under distance education conditions, and correspondingly struggled with increased stress levels. Gender affected stress, with female students experiencing greater stress than male students. The results also reflected the importance of support from lecturers in the distance education process. Finally, the students were generally unsatisfied with the distance education process.

\section{ORCID iDs}

Ayşe Tuğba Ertürk Avunduk (D) https://orcid.org/0000-0002-7879-8150 Ebru Delikan (D) https://orcid.org/0000-0003-1624-3392

\section{References}

1. Wang C, Horby PW, Hayden FG, Gao GF. A novel coronavirus outbreak of global health concern. Lancet. 2020;395(10223):470-473. doi:10.1016/S0140-6736(20)30185-9

2. Gralinski LE, Menachery VD. Return of the coronavirus: 2019-nCoV. Viruses. 2020;12(2):135. doi:10.3390/v12020135

3. Tawfiq Jebril NM. World Health Organization declared a pandemic public health menace: A systematic review of the coronavirus disease 2019 "COVID-19". Int J Psychosoc Rehabilitation. 2020;24(9):2784-2795. doi:10.37200/IJPR/V24I9/PR290311

4. Zhong R. The coronavirus exposes education's digital divide. New York Times. 2020. https://www.nytimes.com/2020/03/17/technology/china-schools-coronavirus.html. Accessed February 20, 2021.

5. Abbasi S, Ayoob T, Malik A, Memon SI. Perceptions of students regarding E-learning during COVID-19 at a private medical college. Pak J Med Sci. 2020;36(COVID19-S4):S57-S61. doi:10.12669/pjms.36. COVID19-S4.2766

6. Sweet J, Wilson J, Pugsley L. Chairside teaching and the perceptions of dental teachers in the UK. Br Dent J. 2008;205(10):565-569. doi:10.1038/sj.bdj.2008.983

7. Quinn B, Field J, Gorter R, et al. COVID-19: The immediate response of European academic dental institutions and future implications for dental education. Eur J Dent Educ. 2020;24(4):811-814. doi:10.1111/eje.12542

8. Sharif M, Rahim S, Tahir A, Minallah S, Sheikh MWL, Riaz MU. Perception of dental students regarding online classes during the pandemic. Pak Armed Forces Med J. 2020;70(1):S369-S374. https://www.pafmj.org/ index.php/PAFMJ/article/view/4935. Accessed February 20, 2021.

9. Asiry MA. Dental students' perceptions of an online learning. Saudi Dent J. 2017;29(4):167-170. doi:10.1016/j.sdentj.2017.03.005

10. Andreou E, Alexopoulos EC, Lionis C, et al. Perceived Stress Scale: Reliability and validity study in Greece. Int J Environ Res Public Health. 2011;8(8):3287-3298. doi:10.3390/ijerph8083287 
11. Cohen S, Kamarck T, Mermelstein R. A global measure of perceived stress. J Health Soc Behav. 1983;24(4):385-396. doi:10.2307/2136404

12. von Elm E, Altman DG, Egger M, Pocock SJ, Gøtzsche PC, Vandenbroucke JP; STROBE Initiative. The Strengthening the Reporting of Observational Studies in Epidemiology (STROBE) statement: Guidelines for reporting observational studies. Ann Intern Med. 2007;147(8):573-577. doi:10.7326/0003-4819-147-8-200710160-00010

13. Rahali K, Abidli Z, Khohmimidi A, et al. Ibn Tofail's University students' satisfaction evaluation towards distance learning and its impacts on the students' mental health during the COVID-19 confinement. Bangladesh J Med Sci. 2020;19:S51-S57. doi:10.3329/bjms. v19i0.48166

14. Halim H, Sulaiman N. Students' perceptions of using information and communication technology as an e-learning method. J Phys Conf Ser. 2020;1529:052093. doi:10.1088/1742-6596/1529/5/052093

15. Schonlau M, Fricker RD, Elliott MN. Conducting Research Surveys via E-mail and the Web. Santa Monica, USA: Rand Corporation; 2002. https://www.rand.org/pubs/monograph_reports/MR1480.html. Accessed February 20, 2021.

16. Denovan A, Dagnall N, Dhingra K, Grogan S. Evaluating the Perceived Stress Scale among UK university students: Implications for stress measurement and management. Stud High Educ. 2019;44(1):120-133. doi:10.1080/03075079.2017.1340445

17. Loubir DB, Serhier Z, Otmani N, et al. Perceived stress: Validation of the translation of a stress measuring scale in Moroccan dialect [in French]. Pan Afr Med J. 2015;21:280. doi:10.11604/pamj.2015.21.280.6430

18. Deery C. The COVID-19 pandemic: Implications for dental education. Evid Based Dent. 2020;21(2):46-47. doi:10.1038/s41432-020-0089-3

19. Onyema EM, Eucheria NC, Obafemi FA, et al. Impact of coronavirus pandemic on education. JEP. 2020;11(13):108-121. doi:10.7176/ JEP/11-13-12

20. Al-Taweel FB, Abdulkareem AA, Gul SS, Alshami ML. Evaluation of technology-based learning by dental students during the pandemic outbreak of coronavirus disease 2019. Eur J Dent Educ. 2020. doi:10.1111/eje.12589

21. de Barros Silva PG, Lima de Oliveira CA, Fontes Borges MM, et al. Distance learning during social seclusion by COVID-19: Improving the quality of life of undergraduate dentistry students. Eur J Dent Educ. 2020;25(1):124-134. doi:10.1111/eje.12583

22. Li M, Hu X, Li X, et al. Dentist-related factors influencing the use of vital pulp therapy: A survey among dental practitioners in China. J Int Med Res. 2019;47(6):2381-2393. doi:10.1177/0300060519843406

23. Hattar S, AlHadidi A, Sawair FA, Abd Alraheam I, El-Ma'aita A, Wahab FK. Impact of COVID-19 pandemic on dental academia. Students' experience in online education and expectations for a predictable practice. 2020. doi:10.21203/rs.3.rs-54480/v1

24. Venkatesh S, Rao YK, Nagaraja H, Woolley T, Alele FO, Malau-Aduli BS. Factors influencing medical students' experiences and satisfaction with blended integrated e-learning. Med Princ Pract. 2020;29(4):396-402. doi:10.1159/000505210

25. Ogan C, Chung D. Stressed out! A national study of women and men journalism and mass communication faculty, their uses of technology, and levels of professional and personal stress. Journal Mass CommunEduc. 2002;57(4):352-369. doi:10.1177/107769580205700405

26. Iyer P, Aziz K, Ojcius DM. Impact of COVID-19 on dental education in the United States. J Dent Educ. 2020;84(6):718-722. doi:10.1002/jdd.12163

27. Mukhtar K, Javed K, Arooj M, Sethi A. Advantages, limitations and recommendations for online learning during COVID-19 pandemic era. Pak J Med Sci. 2020;36(COVID19-S4):S27-S31. doi:10.12669/pjms.36. COVID19-S4.2785

28. Bourzgui F, Alami S, Diouny S. A comparative study of online and face-to-face learning in dental education. EC Dent Sci. 2020;19.3:01-11.

29. Ardies J, De Maeyer S, Gijbels D, van Keulen H. Students attitudes towards technology. Int J Technol Des Educ. 2015;25:43-65. doi:10.1007/s10798-014-9268-x

30. Young BJ. Gender differences in student attitudes toward computers. J Educ Comput Res. 2000;33(2):204-216. doi:10.1080/08886504. 2000.10782310

31. Galibourg A, Delrieu J, Monsarrat $P$, Joniot $S$, Maret D, Nasr K. E-dental practicum: A way to maintain student hands-on training during disruptive crises. J Dent Educ. 2020. doi:10.1002/jdd.12341 